\title{
Perception of Nursing Care among Patients at SRM General Hospital, Kattankulathur, Kancheepuram District
}

\author{
Keerthana S. ${ }^{1}$, Deepika M. ${ }^{1}$, C. Kanniammal ${ }^{2}$, Ushapriya Mathiazhakan ${ }^{3}$ \\ ${ }^{1}$ B.Sc. IV Year Student, SRM College of Nursing, SRMIST, 2 Dean, SRM College of Nursing, SRMIST, \\ ${ }^{3}$ Assistant professor, SRM College of Nursing, SRMIST
}

\begin{abstract}
Background: An significant point that reflects on the understanding of the standard of treatment rendered by the patient is healthcare service. Measuring the experience of nursing care patients can be helpful in improving the quality of nursing services by encouraging the setting of treatment standards and measuring both patient outcomes and quality perceptions.
\end{abstract}

Objectives: The primary aim of this study was to define the understanding of quality nursing care by the patient.

Method: To assess patients' understanding of the quality of nursing care in medical wards and surgical wards of a selected hospital, a cross-sectional descriptive research design was used. A total of 100 patients participated in the study using a purpose-based sampling methodology based on inclusion criteria, such as adult medical and surgical patients 18 years of age or older who spent at least 3 days or more in the hospital. The satisfaction of patients with the quality of nursing care (PSNCQQ) questionnaire, a standardised instrument, was used to assess the perception of the quality of nursing care by patients.

Result: The report showed 89 percent of high-quality care, 11 percent of decent quality nursing care and 0 percent of low-quality nursing care. The great benefit for members of the health care team is enhancing the standard of nursing care according to the understanding of the patient. The primary source of the health care scheme is providing high quality nursing care.

Conclusion: The results showed that nurses should inform patients about the application and protocol and provide sufficient condition, diagnosis and treatment descriptions to ensure patient satisfaction and highquality nursing care.

Keywords: Assess, patients, perception, and nursing care.

\section{Introduction}

A growing trial in any sector would impact the healthcare industry today as well ${ }^{1}$. Healthcare delivery is a central factor that reflects on the patient's understanding of the quality of the care they receive ${ }^{2}$. Assessing the

\section{Corresponding Author:}

\section{Ms. Ushapriya Mathiazhakan}

Assistant Professor, SRM College of Nursing, SRM Institute of Science and Technology, SRM Nagar, Kattankulathur, Chennai, 603203, Tamil Nadu, India e-mail: ushapriyansg@gmail.com quality of nurses' services is vital and so nurses are forced to sustain and enhance the standard of their nursing care ${ }^{3}$ Patients' perception of nursing has been known as the most important indicator of overall patient satisfaction and an essential target of any healthcare organization ${ }^{4}$. Measuring the perception of patients about nursing care may be successful in improving the quality of nursing services by promoting the development of standards for treatment by tracking both outcomes and patients' perceptions of quality ${ }^{5}$.

Patients communicate their needs with respect to what they need, like, want, expect and demand about the nursing care they receive. The understanding of patients 
with the quality of nursing aid is that the required component within the hospital and it is helpful to improve the regular patient-supported reading ${ }^{6}$. Patients may expect more detail on their condition, choices for treatment, procedure, and nursing care. The key objective of health care providers is to achieve excellence in nursing care through the desires and perceptions of the quality of nursing care patients ${ }^{7}$. Hence the purpose of this study was to establish the understanding of quality nursing care by the patient.

\section{Method and Materials}

A descriptive cross-sectional research design was used to test the impression of patients about the quality of nursing care in a selected hospital's medical wards and surgical wards. Complete 100 patients recruited for the study based on inclusion criteria such as adult medical patients aged 18 years or older, who have spent at least 3 days or more in the ward, able to understand Tamil or English and agreed to participate in this study and signed informed consent, and selected patients were interviewed.Before starting the study, the SRMIST had obtained ethical approval. The researcher met each participant and explained the study intent and the instrument. -- participant who decided to complete the instrument was also given written and orally informed consent to take part in the research. Those who were unable to read nor write were aided in completing the questionnaire.

The PSNCQQ was designed to quantify the degree of anticipated need, evaluate patient satisfaction following short-stay hospitalisation, and determine at a minimum level the impact of socio-demographic, personal and other factors ${ }^{8}$ The scale was developed using the Hospital Quality Questionnaire Patient Judgements, developed by a multidisciplinary research team at the Hospital Corporation.of America. The scale was developed for managers to apply in areas needing change, to provide patient-oriented outcomes, and to recognise positive and poor aspects of the nursing care process. Things were focused on variables that were established as essential elements of nursing patient satisfaction. The PSNCQQ can be integrated into current quality control systems in hospitals. Besides, given its relevance to the patient care process as a consequence measure, the PSNCQQ can be used as an evidencebased predictor to detect improvements in departmental and institutional processes. This input gives the nursing administrators valuable knowledge. Replies to the participants are given using a Likert-type 5-point scale. The scoring level was defined as low-quality nursing care $(<50 \%)$, acceptable or good-quality nursing care $(50-75 \%)$, and high-quality nursing care $(>75 \%)$. The original English instrument was translated into Tamil and the reliability was obtained using 0.92 -value SpearmanBrown formula. The data were analysed using statistics of descriptive and inferential type.

\section{Results and Discussion}

Result indicates that $24 \%$ belong to $21-30$ years of age, $17 \%$ belong to $31-40$ years of age, $13 \%$ belong to $41-50$ years of age, $34 \%$ belong to $51-60$ years of age, $12 \%$ belong to $>60$ years of age. As far as sex is concerned, $40 \%$ belong to males and $60 \%$ belong to females. $78 \%$ belong to the Hindu faith, $9 \%$ belong to the Muslims, $13 \%$ belong to the Christians. $75 \%$ of monthly income belongs to $12000-17000,11 \%$ belongs to $17000-22000,13 \%$ belongs to $22000-37000,1 \%$ belongs to $37000-50000000,1 \%$ belongs to 37000 5000000 . As for marital status, $70 \%$ belong to married people, $18 \%$ belong to unmarried people, $2 \%$ belong to divorced people. 58 percent of schooling belongs to primary education, 14 percent to secondary education, 5 percent to diplomas, 17 percent to undergraduates, 6 percent to postgraduates. In terms of occupation, 20 percent belong to specialists, 11 percent belong to technicians, 25 percent belong to skilled employees and business sales workers, 21 percent belong to skilled agricultural and fishery workers, 17 percent belong to elementary workers, 6 percent belong to unemployed workers.As for the area of living, $50 \%$ belongs to urban areas, $50 \%$ to rural areas. 58 percent belongs to only once, 22 percent belongs to twice, 11 percent belongs to three times, 9 percent belongs to $>3$ times, with respect to the number of times hospitalised. 69 percent belong to one week with regard to none of the days hospitalised, 20 percent belong to two weeks, 7 percent belong to 3 weeks, 4 percent belong to $>3$ weeks.

Table 1 : Level of Quality Nursing Care N=100

\begin{tabular}{|c|l|c|c|}
\hline S.No. & Quality of Nursing & $\begin{array}{c}\text { No. of } \\
\text { Respondents }\end{array}$ & Percentage \\
\hline 1 & Low & 0 & $0 \%$ \\
\hline 2 & Good & 11 & $11 \%$ \\
\hline 3 & High & 89 & $89 \%$ \\
\hline
\end{tabular}

Table 1 reveals that $89 \%$ of patients receive highquality nursing care, $11 \%$ receive good-quality nursing care, and $0 \%$ receive low-quality nursing care. 
Table 2: Association between the knowledge level on Nursing Quality and demographic variable $\mathbf{N}=100$

\begin{tabular}{|c|c|c|c|c|c|c|c|}
\hline \multirow{2}{*}{ S.No. } & \multirow{2}{*}{$\begin{array}{l}\text { Demographic } \\
\text { Variable }\end{array}$} & \multirow{2}{*}{ Class } & \multicolumn{2}{|c|}{ Quality of Nursing } & \multirow{2}{*}{$\begin{array}{c}\text { Chi-Square } \\
\text { value }\end{array}$} & \multirow{2}{*}{ DF } & \multirow{2}{*}{ P-value } \\
\hline & & & Good & High & & & \\
\hline \multirow{5}{*}{1} & \multirow{5}{*}{ Ages in years } & 21-30 Years & 3 & 21 & \multirow{5}{*}{1.069} & \multirow{5}{*}{4} & \multirow{5}{*}{0.899} \\
\hline & & 31-40 Years & 1 & 16 & & & \\
\hline & & 41-50 Years & 1 & 12 & & & \\
\hline & & 51-60 Years & 4 & 30 & & & \\
\hline & & $>60$ years & 2 & 10 & & & \\
\hline \multirow{2}{*}{2} & \multirow{2}{*}{ Sex } & Male & 3 & 37 & \multirow{2}{*}{0.834} & \multirow{2}{*}{1} & \multirow{2}{*}{0.361} \\
\hline & & Female & 8 & 52 & & & \\
\hline \multirow{3}{*}{3} & \multirow{3}{*}{ Religion } & Hindu & 9 & 69 & \multirow{3}{*}{0.168} & \multirow{3}{*}{2} & \multirow{3}{*}{0.919} \\
\hline & & Muslim & 1 & 8 & & & \\
\hline & & Christian & 1 & 12 & & & \\
\hline \multirow{4}{*}{4} & \multirow{4}{*}{ Monthly Income } & Rs.12000-17000 & 9 & 66 & \multirow{4}{*}{1.815} & & \\
\hline & & Rs.17000-22000 & 0 & 11 & & 3 & 0612 \\
\hline & & Rs.22000-37000 & 2 & 11 & & 3 & 0.012 \\
\hline & & Rs.37000-50,000 & 0 & 1 & & & \\
\hline & & Married & 8 & 62 & & & \\
\hline 5 & Marital Statur & Unmarried & 2 & 16 & 0271 & 3 & 0065 \\
\hline 3 & Vrantal status & Divorced & 0 & 2 & 0.211 & 3 & 0.905 \\
\hline & & Widowed & 1 & 9 & & & \\
\hline & & Primary education & 5 & 53 & & & \\
\hline & & Secondary education & 2 & 12 & & & \\
\hline 6 & Education & Diploma & 0 & 5 & 4.175 & 4 & 0.383 \\
\hline & & Undergraduate & 2 & 15 & & & \\
\hline & & Postgraduate & 2 & 4 & & & \\
\hline & & Professionals & 3 & 17 & & & \\
\hline & & Technicians & 2 & 9 & & & \\
\hline 7 & & Skilled workers and Market sales worker & 2 & 23 & & 5 & \\
\hline 7 & Occupation & Skilled agricultural and Fishery worker & 2 & 19 & 6.341 & 5 & 0.274 \\
\hline & & Elementary occupation & 0 & 17 & & & \\
\hline & & Unemployed & 2 & 4 & & & \\
\hline 8 & & Urban & 4 & 46 & 0010 & 1 & 0338 \\
\hline 8 & Area of living & Rural & 7 & 43 & 0.919 & 1 & 0.338 \\
\hline & & Only once & 7 & 51 & & & \\
\hline 0 & No.of times & Twice & 1 & 21 & 6040 & 3 & 0074 \\
\hline 9 & hospitalized & 3 times & 0 & 11 & 0.949 & 3 & $0.0 / 4$ \\
\hline & & $>3$ times & 3 & 6 & & & \\
\hline & & 1 week & 9 & 60 & & & \\
\hline 10 & No.of days & 2 week & 1 & 19 & 1601 & 3 & 0650 \\
\hline 10 & hospitalized & 3 week & 1 & 6 & 1.001 & 3 & 0.059 \\
\hline & & $>3$ week & 0 & 4 & & & \\
\hline
\end{tabular}

*Significant at $5 \%$ level **-Significant at $1 \%$ level 
Communication skills of health professionals play a pivotal role in ensuring patients feel valued and taken care of. Allocating sufficient time to speak and listen to patients and providing information is a prerequisite for patient satisfaction, as it ensures patients are less stressed and more engaged and well-adjusted. The study's first aim of evaluating the perception of nursing care among patients at SRM General Hospital. The result revealed that 89 percent of patients receive high-quality nursing care, 11 percent of patients receive good quality nursing care and 0 percent receive low-quality care. Khan et al., 2007 conducted a study on patient satisfaction with Henderson's basic model of nursing aid regarding medical aid. The study did not hide the fact that fortyfifth patients were happy about the quality of nursing aid and fifty-five were partially unhappy about the quality of medical aid and nineth patients didn't feel like talking to a worker nurse 9 .

The study's second aim to link the perception of nursing care among patients with their selected demographic variables. No significant association exists between the opinion regarding nursing quality and patient demographic variables $(\mathrm{p}<0.055)$. Lumby (2005) conducted a study with a valid form, four hundredth of the population, on patient satisfaction with medical aid. According to the current study, eighty-four patients were happy with nursing aid and fifty-four patients did not feel comfortable talking to nurses. Patients' full age, sex, and educational levels had no significant influence on patient satisfaction in this study. Lots of sample size required to validate ${ }^{10}$.

\section{Conclusion}

The results showed that $89 \%$ of high-quality care, $11 \%$ good quality nursing care and $0 \%$ low-quality nursing care. Nurses should inform patients about each application and procedure, and provide the necessary explanations about disease, diagnosis, and treatment to ensure patient satisfaction and quality nursing care.

Acknowledgements: We would like to thank the management, principal, superintendent of nursing and staff at the hospital concerned for their cooperation and support.

Authors' Contributions: I wish to express my heartfelt gratitude to the participants who have given willingness to take part in the study.

Conflicts of Interest: No conflicts of interest exist.

Authors' Funding: Self.

\section{References}

1. Alsaqri, S. Patient satisfaction with the quality of nursing care at governmental hospitals, Ha'il City, Saudi Arabia. Journal of Biology, Agriculture and Healthcare, 2016;6(10), 128- 142. Google Scholar.

2. Törnvall E, WilhelmssonS .Quality of nursing care from the perspective of patients with leg ulcers. J Wound Care .2010;19: 388-395. [Crossref]

3. Zhao SH, Akkadechanunt $\mathrm{T}$, XueXL .Quality nursing care as perceived by nurses and patients in a Chinese hospital. J Clin Nurs .2009;18: 17221728. [Crossref]

4. Goh, M. I., Ang, E. N. K., Chan, Y. H., He, H. G., \& VehvilainenJulkunen, K. A descriptive quantitative study on multi-ethnic patient satisfaction with nursing care measured by the revised humane caring scale. Applied Nursing Research, 2016;31, 126131. https://doi.org/10.1016/j.apnr.2016.02.002 Crossref PubMed Web of Science ${ }^{\circledR}$ Google Scholar

5. Akın, S., \& Erdoğan, S. The Turkish version of the Newcastle satisfaction with nursing care scale used on medical and surgical patients. Journal of Clinical Nursing, 2007; 16, 646-653. https://doi.or g/10.1111/j.1365-2702.2006.01583.xWiley Online Library CAS PubMed Web of Science ${ }^{\circledR}$ Google Scholar

6. Suhonen R, Papastavrou E, Efstathiou G, Tsangari H, Jarosova D, Leino-Kilpi H, Patiraki E, Karlo C, Balogh Z, Merkouris A. Patient satisfaction as an outcome of individualized nursing care. Scand J Caring Sci. 2012;26(2):372-380. DOI: 10.1111/j.1471-6712.2011.00943.x. [PubMed] [CrossRef] [Google Scholar]

7. Varkey P, Reller MK, ResarRK. Basics of quality improvement in health care. Mayo Clin Proc. 2007;82:7359. DOI: 10.1016/S00256196(11)61194-4. [PubMed] [CrossRef] [Google Scholar].

8. Laschinger. Psychometric Analysis of Patient Satisfaction WithNursing Care Quality Questionnaire: An Actionable Approach to MeasuringPatient Satisfaction, Journal of Nursing Care Quality. 2005; 20 (3), 220-230.

9. Khan et al. Patient Satisfaction with Nursing Care. Rawal Medical Journal: 2007; Vol.32, No.1, Jan.June.

10. Lumby, J. Patient satisfaction with nursing care in a colorectalsurgical population, International Journal of Nursing Practice, 2005; 6(3), 140-145,2005. 